\title{
Behavioral responses of Steirastoma breve (Sulzer) (Coleoptera: Cerambycidae) to host plant Theobroma cacao L., brushwood piles, under field conditions
}

\author{
Carmen V. Liendo-Barandiaran, ${ }^{1, *}$ Beatriz Herrera-Malaver, ${ }^{1}$ Franklin Morillo, ${ }^{2}$ \\ Pedro SÁnChez ${ }^{2}$ and José V. Hernández ${ }^{1, *}$ \\ ${ }^{1}$ Universidad Simón Bolívar, Biología de Organismos, Laboratorio de Ecología Química del Comportamiento; Caracas, 1080A- \\ Venezuela \\ ${ }^{2}$ Instituto Nacional de Investigaciones Agrícolas, Estación Experimental Miranda, Calle El Placer; Caucagua, Estado Miranda- \\ Venezuela
}

(Received 10 September 2009; Accepted 27 May 2010)

\begin{abstract}
Steirastoma breve is one of the most important pests in cocoa plantations in the Neotropics. Preliminary studies suggest that the chemical communication system in $S$. breve may be modulated by kairomones produced by cocoa plants and pheromones released by males. We examined the role of Theobroma cacao brushwood in the communication system of $S$. breve under field conditions. Sixty kilograms of T. cacao and Bauhinia sp. branches were cut, grouped into separate piles, and placed in an experimental cocoa plantation as an odor source. The sex and number of $S$. breve adults landing on each pile were registered during 23 days from 9:00 to 15:00 h. Each individual arriving at a pile was marked with a coded color and then released onto the same pile. All behavioral activities undertaken by $S$. breve were evaluated and flight behavior towards the $T$. cacao piles was described. S. breve adults were attracted to $T$. cacao piles placed under both sunny and shaded conditions, but were not attracted to Bauhinia sp. S. breve males dispersed more in shaded piles than in those placed in the sun, and the proportion of encounters between sexes was higher in the piles at which they had first arrived. Analysis of the data confirmed the presence and importance of $T$. cacao kairomones in the chemical communication system of this important cocoa pest.
\end{abstract}

Key words: Steirastoma breve; Theobroma cacao; kairomones; Cerambycidae; communication system

\section{INTRODUCTION}

Hines and Heikkenen (1977) first provided evidence of the capacity of Cerambycidae to locate their hosts in the field by means of semiochemical signals. Several chemical compounds of vegetal origin have been reported that attract the following Cerambycidae species: Monochanus alternatus (Ikeda et al., 1980; Sakai and Yamasaki, 1990, 1991), Phoracantha semipunctata (Barata et al., 2000), Anaglyptus subfasciatus, Demonax transilis (Ikeda et al., 1993; Nakashima et al., 1994), Hoplocerambyx spinicornus (Varshney et al., 2005), Tetropium fuscum, T. castaneum and T. cinnamopterum (Sweeney et al., 2004, 2006). However, most of these studies were performed under laboratory conditions and few field behavioral studies have been performed using vegetal odors as Cerambycidae attractants. Field tests with kairomone-baited traps were conducted only to determine the efficiency of attractants for the capture of adults (Nakamuta et al., 1997; Reddy et al., 2005)

Steirastoma breve (Cerambycidae: Lamiinae), commonly known in Venezuela as the "Cocoa beetle", is one of the main pests of Theobroma cacao L. (Malvaceae) plantations in South America and some Caribbean islands (Entwistle, 1972; Sánchez and Capriles de Reyes, 1979). The larvae and adults of this pest species cause severe damage to the branches and stems of cocoa plants; adult females rip the bark with their mandibles and lay

\footnotetext{
* To whom correspondence should be addressed at: E-mail: liendocv@usb.ve; jnandez@usb.ve
} DOI: $10.1303 /$ aez.2010.489 
their eggs inside. When the larvae emerge, they feed on the vascular system, opening irregular galleries that may cause stem or branch ringing, which leads to plant or branch death. Adults also scrape the bark of branches and stems to feed, thus facilitating infestation by pathogenic micro-organisms. Additionally, damage to floral clusters can occur, thereby causing important economic losses. Olfactometric and electroantennographic studies under laboratory conditions showed that the odors released from $S$. breve males and pieces of $T$. cacao branches attract adults (males and females) of this pest species. These results suggest that the chemical communication system in $S$. breve may be modulated by kairomones produced by cocoa plants and pheromones released by males (Liendo et al., 2005).

A simple method for controlling most cocoa pests and pathogens is to manage shade by pruning cocoa trees and trees which are normally used for permanent shade (Erythrina glauca: Fabaceae) in cocoa plantations (Mendes and García, 1984). Cocoa plants are usually pruned as good agronomic practice for the proper maintenance of plantations, and the cut branches are left on the ground to decompose. In this study, we examined the role of $T$. cacao cut branches (brushwood) in the communication system of $S$. breve under field conditions. Also, we attempted to investigate the behavior of $S$. breve towards host plant brushwood piles over time, in order to determine the following: 1) when the piles become most attractive to $S$. breve adults; 2) other kinds of behavioral responses to the host; and 3) patterns of dispersion of $S$. breve adults with respect to other nearby $T$. cacao brushwood piles.

\section{MATERIALS AND METHODS}

Study sites. Bioassays were carried out in several T. cacao plots at the Padrón experimental field station $10^{\circ} 13^{\prime} 36^{\prime \prime} \mathrm{N}, 66^{\circ} 18^{\prime} 30^{\prime \prime} \mathrm{W}, 41 \mathrm{MSL}$, owned by the Instituto Nacional de Investigaciones Agrícolas (INIA), Miranda State, Venezuela. Field bioassay A was carried out between October 4 and October 27, 2004, and field bioassay B was carried out between October 30 and November 20, 2006. During the study, the average temperature was $27.4^{\circ} \mathrm{C}$; relative humidity, $95 \%$; and the evaporation and precipitation rates were 6.3 and $4.3 \mathrm{~mm}$, respectively.

Olfactory behavior of $S$. breve towards $T$. cacao and Bauhinia sp. brushwood piles

Bioassay A (without removing S. breve adults). Sixty kilograms $T$. cacao branches from healthy adult plants were cut and placed in piles to be used as an odor source for the bioassay. Two treatments were employed: some piles were exposed to the sun whereas others where left in the shade. Likewise, $60 \mathrm{~kg}$ Bauhinia sp. (Fabaceae) (a common species in this region, but not reported as a $S$. breve host) was used as a control for each treatment. All piles were distributed in the experimental plots along straight line transects, perpendicular to the predominant wind direction, and separated by 20 m. Four T. cacao and two Bauhinia sp. branch piles were randomly placed in each of the two treatments (shade and sun) and observations began the day after setting up the bioassay. For each pile, both the number and sex of all $S$. breve beetles found were registered from 9:00 to 15:00 h over a period of $23 \mathrm{~d}$. Observers were randomly changed each day.

The data obtained from the application of both treatments (shade and sun) were analyzed using a balanced nested ANOVA. Sex, day and time were preselected as fixed factors. Comparison between factors was performed using the Bonferroni $t$-test.

Bioassay $B$ (removing $S$. breve adults). In order to verify if the odor from $T$. cacao brushwood piles by itself was attractive to $S$. breve adults, we carried out the following experiment. This bioassay was conducted in the same way as bioassay A, except for three changes: 1) all piles were placed in the shade, 2) all $S$. breve adults found on T. cacao brushwood piles were immediately removed from the pile, and 3) for each pile, the number and sex of $S$. breve beetles found were registered between 11:00 and 15:00 h, every two days from day six to day 17 after the start of the bioassay. The mean numbers of $S$. breve males and females per observation day were calculated by main effects ANOVA.

$S$. breve behavior on $T$. cacao piles. During bioassay A, the observer also made hourly observations of the behavioral activities performed by $S$. breve individuals under sunny and shady conditions, including the flight behavior of each beetle when approaching the odor source (T. cacao brushwood). 
Capture, mark and release of $\boldsymbol{S}$. breve adults on $T$. cacao piles. $S$. breve adults found on the piles during bioassay A were captured and marked using nail polish. A different color code was assigned to each pile. Males were marked on the right elytra and females on the left elytra. These marks permitted us to register the presence of these same individuals on the same or different brushwood piles, without further manipulation. When an adult first arrived at a pile, it was marked with the respective color for that pile and then carefully released on the same pile. Registers were made of all marked individuals found on each pile. Data obtained on days when the greatest average number of individuals arrived at the piles were analyzed using the Kruskal-Wallis test.

\section{RESULTS}

Olfactory behavior of $S$. breve towards $T$. cacao and Bauhinia sp. brushwood piles

Bioassay A (without removing S. breve adults)

The average number of adult males found on shaded T. cacao piles $(0.92 \pm 0.07$; mean \pm SE) was higher than that found on piles placed in the sun (0.65 \pm 0.05$)$ (Fig. $1 \mathrm{~A} ; n=161 ; \quad F=9.006 ; p=$ 0.003; ANOVA test). Similarly, the average number of adult females was higher on shady piles $(0.49 \pm$ $0.05)$ than on sunny piles $(0.30 \pm 0.03) \quad(n=161$; $F=8.391 ; p=0.004$; ANOVA test).

The total average number of $S$. breve males observed on $T$. cacao brushwood piles was higher than that of females, both under sunny (Fig. 1A, $F=31.290 ; p=0.0001 ;$ ANOVA test) and shady conditions $(F=43.298$; $p=0.0001$; ANOVA test $)$. A significant interaction effect between treatment and sex was not detected $(n=161 ; F=0.4320$; $p=0.4320$; ANOVA test). No $S$. breve adults were observed on Bauhinia sp. brushwood piles during the $23 \mathrm{~d}$ of the experiment.

The average number of $S$. breve females found on $T$. cacao piles placed in the sun was highest on day nine at $13: 00 \mathrm{~h}$ (Fig. $2 \mathrm{~A}$ and $2 \mathrm{~B}, n=161$; $F=1.382 ; p=0.0259$; ANOVA test). The highest average number of males on the piles was found at $11: 00 \mathrm{~h}$ (Fig. 2A and 2B, $n=161 ; \quad F=1.62$; $p=0.0018$; ANOVA test). Under shady conditions, the average number of both $S$. breve females and males found on T. cacao piles was highest on days 12 and 13 (Fig. 2C). The highest average number
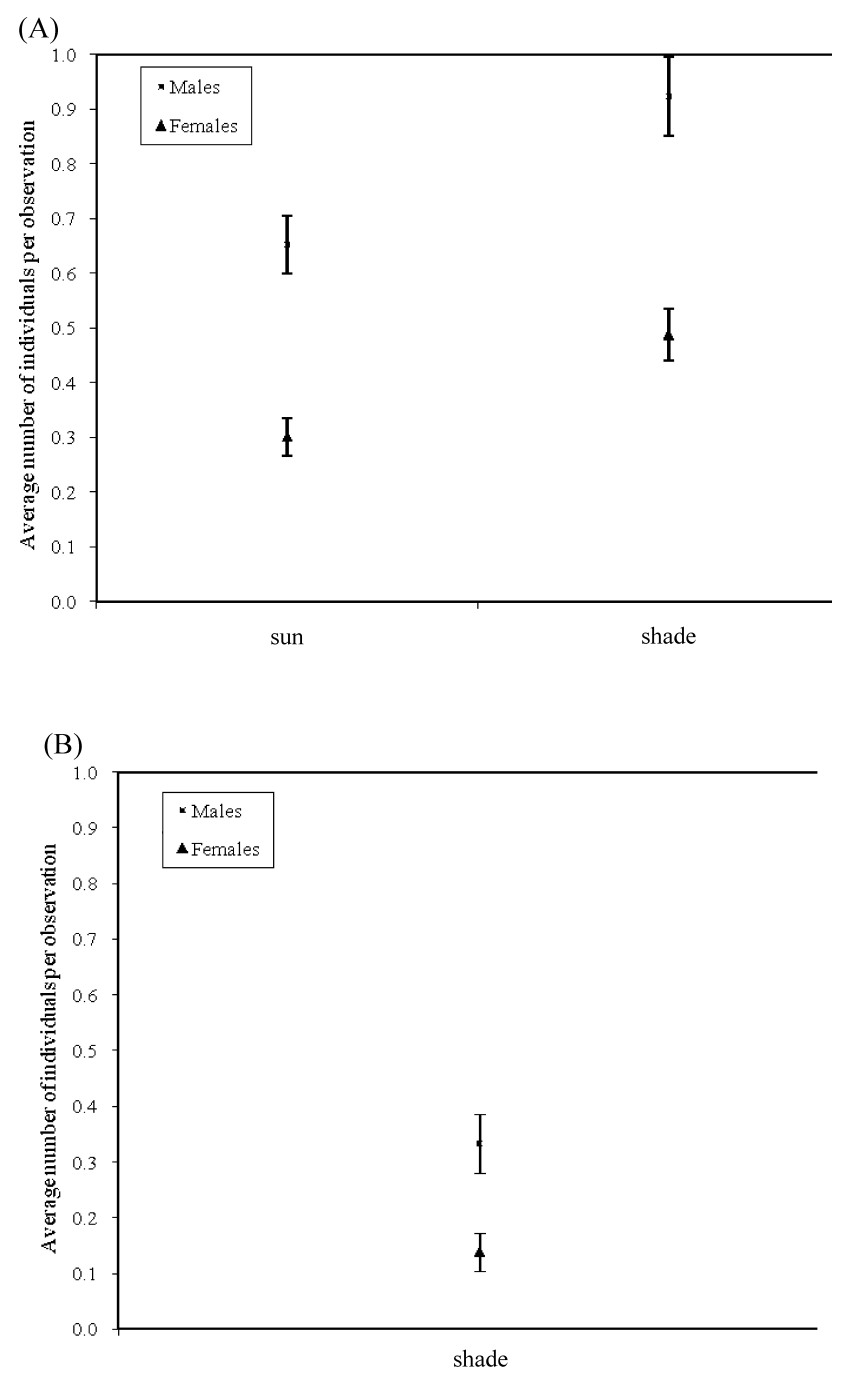

Fig. 1. (A) Bioassay A (without removing Steirastoma breve adults): Average number of Steirastoma breve males and females (individuals per treatment $\pm \mathrm{SE}$ ) found on Theobroma cacao piles under sunny and shaded conditions. Balanced nested ANOVA using treatment and sex as fixed factors indicate the following significance levels: $p$ (treatment $)<0.0001 ; p$ $(\operatorname{sex})<0.0001 ; p($ treatment $\times$ sex $)=0.4320$. (B) Bioassay B (removing Steirastoma breve adults): Average number $( \pm \mathrm{SE})$ of Steirastoma breve males and females found on Theobroma cacao piles.

of females was found at 13:00 h (Fig. 2D; $n=161$; $F=7.19, p=0.0001$; ANOVA test) and that of males from 12:00 to 15:00 h (Fig 2D; $n=161$, $F=11.39 ; p=0.0001$; ANOVA test).

Under sunny conditions, the average number of both $S$. breve males and females observed on $T$. cacao piles varied from day to day during the first nine days; beetle attraction first increased, and then steadily declined. In contrast, under shaded condi- 

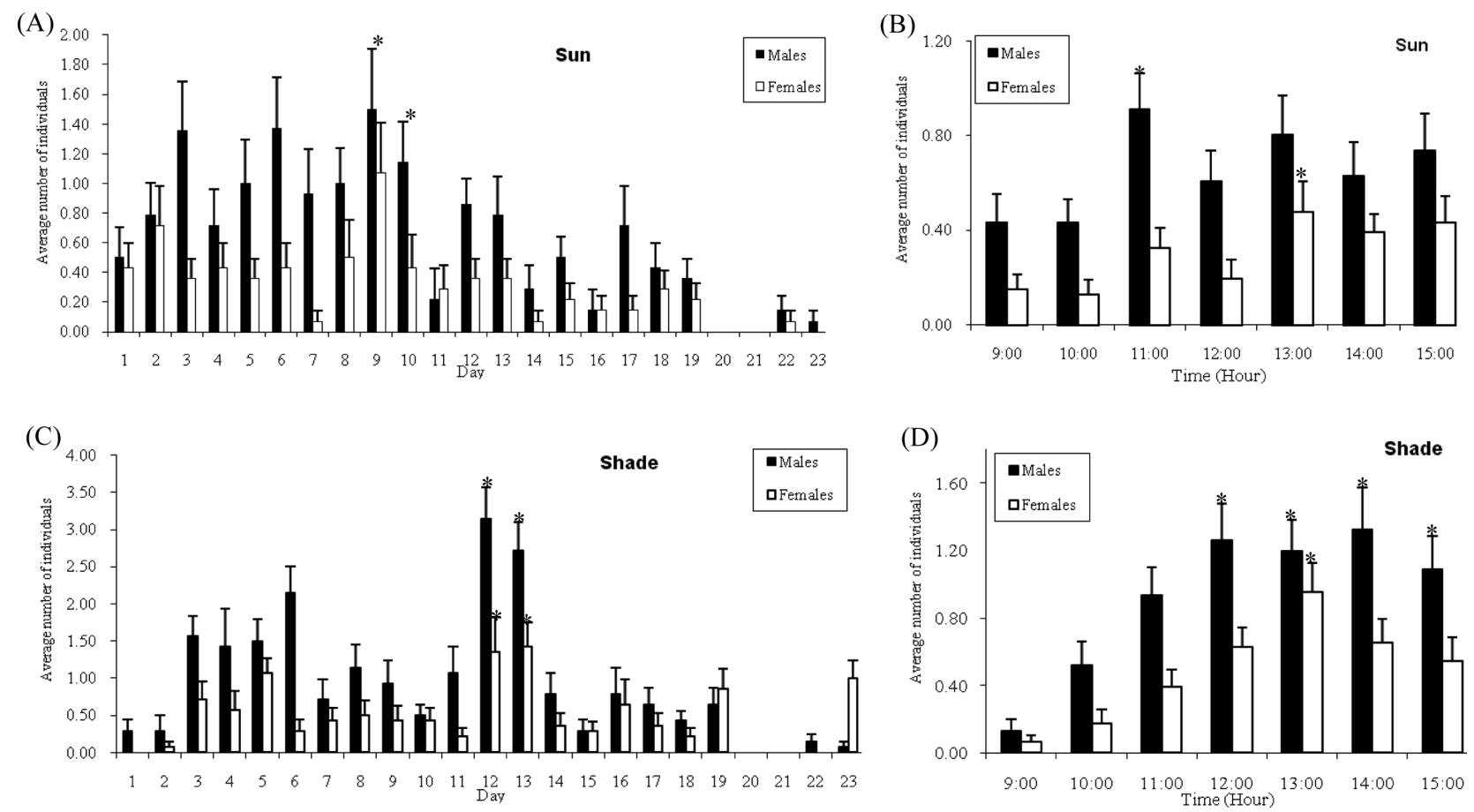

Fig. 2. Average number of males and females (individuals $\pm \mathrm{SE}$ ) of Steirastoma breve adults found on Theobroma cacao piles under sunny $(\mathrm{A}$ and $\mathrm{B})$ and shaded $(\mathrm{C}$ and $\mathrm{D})$ conditions at different times $(\mathrm{B}$ and $\mathrm{D})$, over $23 \mathrm{~d}(\mathrm{~A}$ and $\mathrm{C})$. Bars with asterisks $(*)$ indicate statistically significant differences, as shown by the Bonferroni $t$-test, $p<0.05$.

tions, a different attraction pattern was observed. During the first eight days, only a few individuals were attracted. From day 10 to 14 attraction increased to a maximum, and then decreased until the end of the bioassay.

Bioassay $B$ (removing S. breve adults)

The average number of males $(0.33 \pm 0.08)$ collected on $T$. cacao piles was higher than that of females (0.14 \pm 0.04$)$ (Fig. $1 \mathrm{~B} ; n=72 ; F=5.194$; $p=0.024$; ANOVA test). These results are consistent with those obtained during bioassay A.

\section{S. breve behavior on $T$. cacao branches}

The different behaviors exhibited by $S$. breve were characterized as: resting, mating, flying, exploring, oviposition, agonistic and feeding. Resting behavior was the main activity performed by both sexes under both bioassay conditions (sunny and shady); however, the proportion of resting behavior was always slightly higher in males than in females. Exploratory behavior occurred from 9:00 to 15:00 h on both sunny and shady piles, just within the time during which field observations started and ended. Exploratory behavior was defined as when $S$. breve adults walked whilst simultaneously moving their antennae on $T$. cacao brushwood piles.

The maximum number of individuals undergoing mating behavior was at 14:00 h (Fig. 3), as was the maximum number of females flying, both in the sun and in the shade (Sun: Fig. 3A, $n=7,37 \%$ in flight); (Shade: Fig. 3C, $n=8,20 \%$ in flight). The time of maximum male flight was at 10:00 h (Fig. $3 \mathrm{~B}, 23 \% ; n=10$ ) in the sun, and 11:00 h (Fig. 3D, $35 \%, n=21)$ in the shade.

In both treatments, the proportion of males feeding on the piles was higher than that of females (male : female $=3: 1$, on sunny piles; and $2: 1$ on shaded piles).

Neither oviposition behavior nor intra or intersexual agonistic behavior was observed on piles placed in the sun. On shaded piles, however, the maximum number of females ovipositing $(10 \%)$ was at $14: 00 \mathrm{~h}$. Agonistic interactions between males $(6 \%, n=62)$ were also observed.

The approach behavior of $S$. breve towards $T$. cacao piles seemed to be random, and flight activity occurred at a height of approximately $1 \mathrm{~m}$ above the soil. Three kinds of movements were observed: zigzag, straight line and round-the-pile 

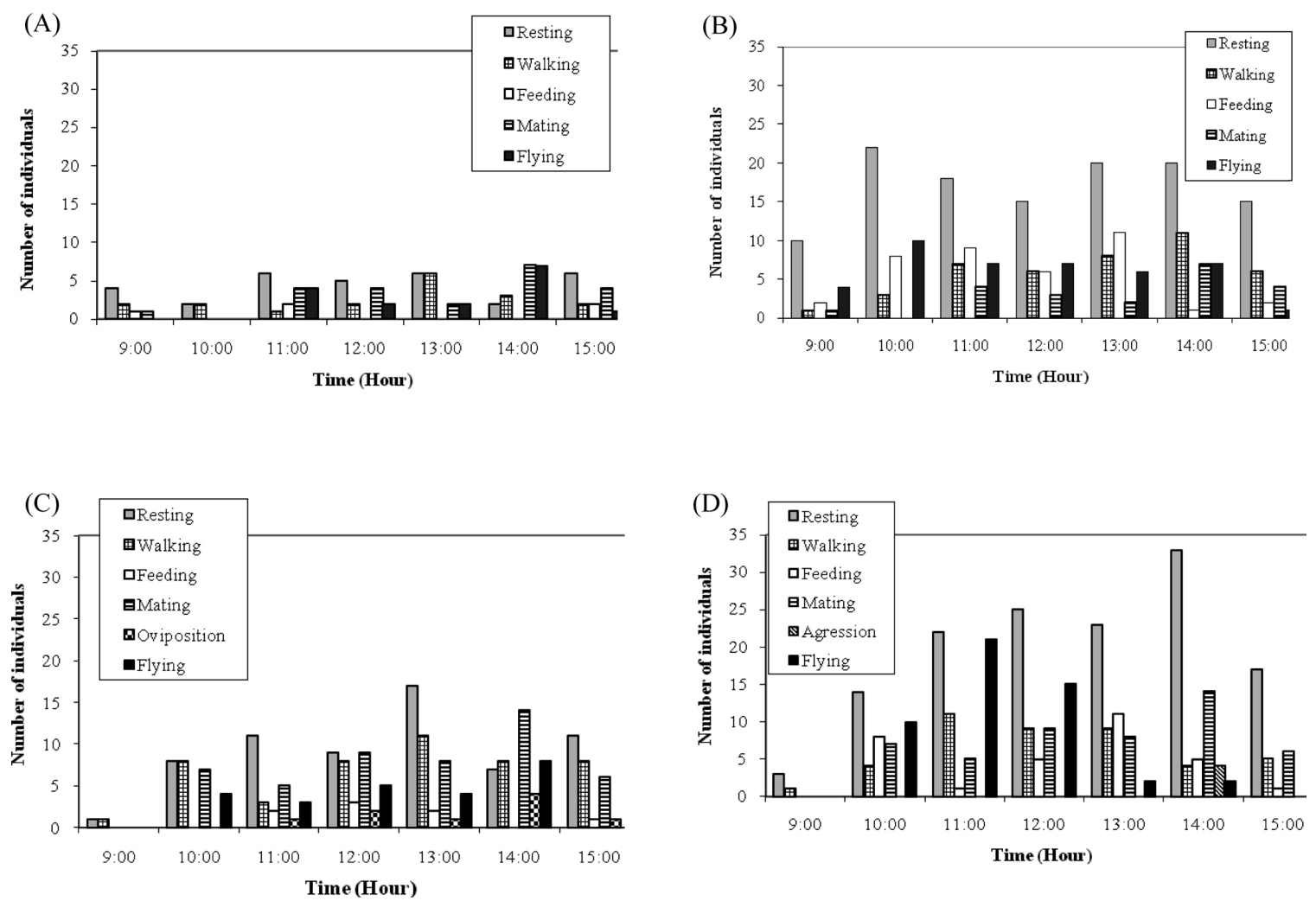

Fig. 3. Ethograms of adult Steirastoma breve activity on Theobroma cacao piles from 9:00 to 15:00 h over 23 days (A): Sunny females; (B): Sunny males; (C): Shaded females; and (D): Shaded males.

flight. In general, straight-line flight was the most frequent $(56 \%, n=32 ; 66 \%, n=44$, respectively), followed by zigzag flight ( $28 \%$ under sunny conditions and $16 \%$ in the shade). Round-the-pile flight was the least frequent (16\% sunny and $18 \%$ shaded conditions) also observed at that time.

\section{Capture, mark and release of $S$. breve adults on} T. cacao piles

Under sunny conditions, more $S$. breve males were recaptured from the piles where they had first landed compared to recaptures from neighboring or non-neighboring piles, or individuals captured for the first time (Fig 4A; $n=19 ; p=0.0272$; KruskalWallis test). When making the same comparisons among females, however, no significant differences were found.

In contrast, under shady conditions, the results were different: more males returned to either the pile where they had first landed or to a neighboring pile, compared to those (marked) males visiting non-neighboring piles and first time arrivals (Fig. 4B; $n=40 ; p<0.0001$; Kruskal-Wallis test). Re- garding $S$. breve females, a higher proportion returned to the pile they had previously landed on compared to those returning to neighboring and non-neighboring piles and first-time arrivals. (Fig. 4B; $n=40 ; p=0.0001$; Kruskal-Wallis test).

\section{DISCUSSION}

T. cacao piles exposed to sunny and shaded conditions attract $S$. breve adults, whereas Bauhinia sp. piles do not. This attraction effect could be caused by an olfactory stimulus derived from volatile compounds released by T. cacao brushwood and/or $S$. breve adults (Fig. 1A). The T. cacao piles maintained their attractiveness even when $S$. breve adults were removed (Fig. 1B), indicating that volatile compounds, possibly kairomones, from $T$. cacao piles attracted $S$. breve adults.

Hanks (1999) categorized Cerambycidae species according to the condition of the larval host: healthy, weakened, stressed or dead; however, our findings suggest that $S$. breve belongs to more than one Hanks category. $S$. breve adults do not colonize 

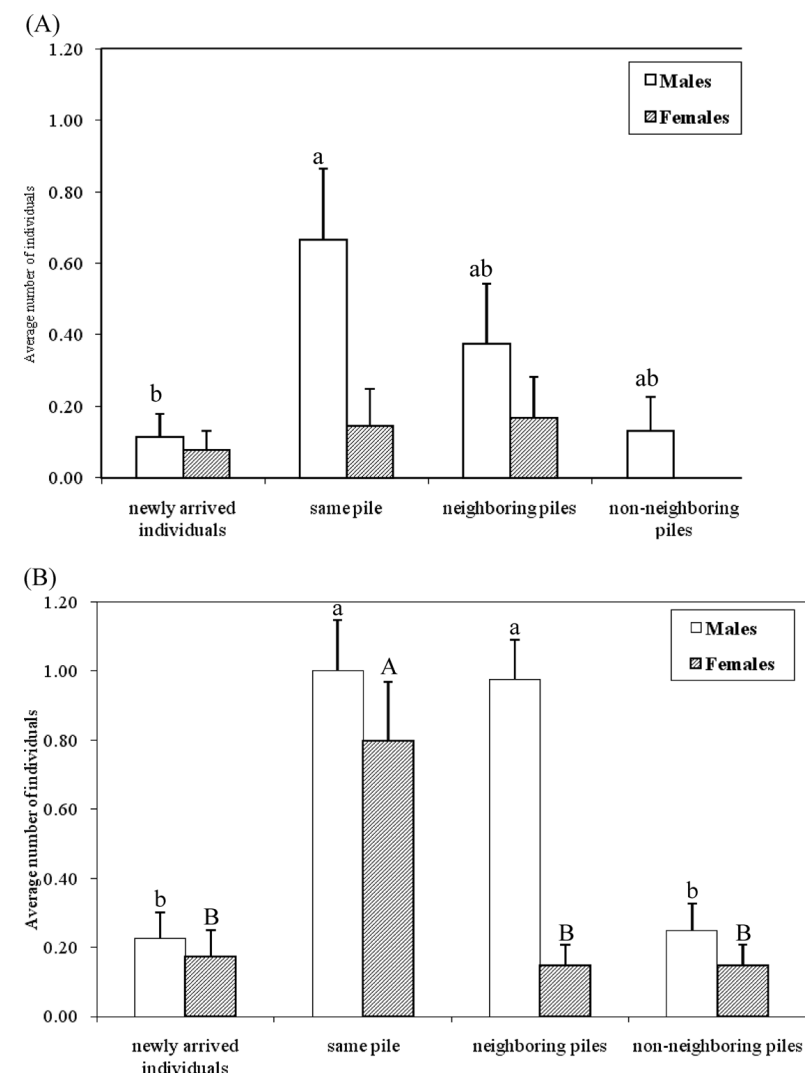

Fig. 4. Average number of marked and non-marked Steirastoma breve males and females (individuals/pile $\pm \mathrm{SE}$ ), found on Theobroma cacao piles under sunny (A) and shady conditions (B).

apparently healthy cocoa host plants, but they may do so as a result of agronomic practices, such as pruning. Freshly cut cocoa branches, such as those we evaluated, are still alive, and provide a large artificial source of damaged tissues emitting odors that could be attractants (kairomones) for $S$. breve adults. For example, sesquiterpene hydrocarbons, involved in the communication system of Anoplophora malasiaca at both long and short ranges, have been isolated from wounded host plants (Citrus unshiu) (Yasui et al., 2008; Yasui, 2009). Kairomones are often used by Cerambycidae as part of their communication system and have been used as bait to catch adult beetles regarded as agricultural pests, for example, Arhopalus tristis (Suckling et al., 2001), M. alternatus (Ikeda et al., 1980; Fan et al., 2007), Tetropium fuscum and T. castaneum (Sweeney et al., 2004, 2006). Kairomones have been classified into four groups, according to how they benefit the receiving organism: foraging, enemy avoidance, sex and aggregation kairomones (Ruther et al., 2002).

In a similar study conducted with Xylotrechus quadrupes, the coffee white stemborer, one of the control measures evaluated consisted of maintaining good shade because adults are more active in sunlight (Hall et al., 2006). The opposite situation was observed in $S$. breve, where adults were more active on shaded piles.

Variations in beetle attraction towards T. cacao piles under field conditions may be related to variations in the proportions of plant and male volatiles over the 23 days of the experiment, as has been observed in other Cerambycidae species, for example, the number of Phorocantha semipunctata adults caught using sticky traps placed on the stems of different Eucalyptus species. During the first few days, captures were minimal, but then increased until day 30 when the maximum capture rate was reached (Hanks et al., 1993). Analyses of kairomones emitted by the Japanese pine tree, the host of M. alternatus, showed variations in the proportions of compounds such as $\alpha$-pinene, limonene and $\beta$-phelandrene over time. Field bioassays showed that these variations affect the attraction of M. alternatus to the pines (Ikeda et al., 1980). In our case, the results of bioassay A showed that a major proportion of males arrived on both sunny and shaded piles before females (Fig. 2). Thus, females may be attracted to the volatiles from both $T$. cacao and male pheromones. Electroantennographic and olfactory responses of $S$. breve individuals under laboratory conditions suggest that males may produce and release a sex pheromone to attract females (Liendo et al., 2005). This may explain why females appear to be more active than males in mate searching behavior and also why resting behavior during the day was slightly higher in males than in females (Fig. 3A-D). This is not the case for most Cerambycidae, in which males actively search for pheromone-releasing females; however, the present study supports the existing evidence (Hanks, 1999) that sedentary individuals are responsible for pheromone production and therefore for attracting the opposite sex.

The maximum number of $S$. breve copulating on T. cacao brushwood piles was observed at $14: 00 \mathrm{~h}$, under both sunny and shady conditions (Fig. $3 \mathrm{~A}-\mathrm{D})$. The total number of males and females registered on the piles was also highest at this time. 
The maximum number of $M$. alternatus mating under field conditions was observed between 22:00 and 2:00 h (Fauziah et al., 1987), whereas for Nadezhdiella cantori this was observed from 17:00 to $24: 00 \mathrm{~h}$ under laboratory conditions (Wang et al., 2002). In the present study, the highest registers of mating found coincided with the oviposition and flight activity of $S$. breve females. Wang et al. (2002) report similar findings for N. cantori. Agonistic behavior among $S$. breve males during mating activity was observed. This has also been reported for M. saltuarius (Kobayashi et al., 2003). The male-female ratio reported for $S$. breve under laboratory conditions was 2:1 (Mendes and García, 1984), consistent with our field results (Fig. 1). Similar results have been reported for $M$. alternatus (Lamiinae) during both field and laboratory behavioral bioassays using monoterpenes and ethanol as attractants (Ikeda et al., 1980; Fan et al., 2007).

In tropical regions, most Cerambycidae species fly at sunset, night or sunrise. Although a systematic study of flight behavior in Cerambycidae does not exist, it is generally thought that their flight usually follows a slow straight path towards the odor source (Hanks, 1999). We found, however, that the flight behavior of $S$. breve towards the $T$. cacao brushwood piles appeared to be random. We observed that after 15:00 h, the individuals left the piles and flew towards unknown locations. During the observation period, this behavior was very variable, sometimes walking, feeding, mating, resting or even flying away or returning to the pile. This species did not only remain on the pile for feeding, as was described above, but also moved to other locations, possibly to search for mates.

The catch-mark-release results of $S$. breve adults on $T$. cacao piles show that shady conditions encourage the encounters of both sexes on brushwood piles (Fig 4B). Individual males and females also tended to return to the same pile where they had first landed; thus, they may produce other semiochemicals that act as marker for returning to previously visited piles. The biological basis of marking pheromones has been demonstrated in Cerambycidae; however, the compounds involved have not yet been isolated and characterized. In general, these pheromones are identified as oviposition pheromones and are used to mark, detect and avoid hosts occupied by con-specific individuals
(Allison et al., 2004). Further research is necessary in order to confirm the existence of an oviposition or marking pheromone in $S$. breve.

Based on this classification, the results of bioassays A and B suggest the existence of aggregation kairomones emitted by $T$. cacao, which attract both $S$. breve males and females. Once both sexes are on a brushwood pile, their encounters may be mediated by different types of pheromones. Further studies are necessary to investigate this hypothesis.

In conclusion, this study confirms that the vegetal kairomone emitted by cut $T$. cacao branches attracts $S$. breve adults.

\section{ACKNOWLEDGMENTS}

This research was financially supported by the "Proyecto de Investigación en Red en el marco de la Ruta del Chocolate $\mathrm{N}^{\mathrm{o}}$ 200500898; Subproyecto 7: Estudio y validación de alternativas de control etológico de insectos plagas del cacao: Steirastoma breve (Sulzer) (Coleoptera: Cerambycidae) y Carmenta foraseminis (Busck) (Lepidoptera: Sesiidae) en el estado Miranda", and GID-012 from the Universidad Simón Bolívar. We would like to thank Jerónimo Guerra and Wilfredo Muñoz of INIA-Miranda for the installation of the bioassays and collecting the insects used in this study. We would also like to thank Pedro Romero, Andreina Acosta, Gerson Bolet, Pedro Hurian, Astrid Florez, Esther Tintin, Angie Rengifo, Pablo Pereira, Johanny Pacheco, José E. Piñango, Danny Cones y César I. Liendo for field assistance. Thanks are also due to Cristina Sainz, Alexander Natera and Johan Billen for critical revision of the manuscript, and Mayida El Souki for her valuable suggestions on the statistical analysis. Finally, a special thanks to Jorge González, Andrés Algara and Frances Osborn for their critical revision of the manuscript and translation into English.

\section{REFERENCES}

Allison, J., J. Borden and S. Seybold (2004) A review of the chemical ecology of the Cerambycidae (Coleoptera). Chemoecology 14: 123-150.

Barata, E., J. Pickett, L. Wadhams, C. Woodcock and H. Mustaparta (2000) Identification of host and nonhost semiochemicals of Eucalyptus woodborer Phoracantha semipunctata by gas chromatography-electroantennography. J. Chem. Ecol. 26: 1877-1895.

Entwistle, P. (1972) Pests of Cocoa. Longman, London. $779 \mathrm{pp}$.

Fan, J., L. Kang and J. Sun (2007) Role of host volatiles location by the Japanese pine sawyer, Monochamus alternatus Hope (Coeloptera: Cerambycidae). Environ. Entomol. 36: 58-63.

Fauziah, B., T. Hidaka and K. Tabata (1987) The reproductive behaviour of Monochamus alternatus Hope (Coleoptera: Cerambycidae). Appl. Entomol. Zool. 22: 272-285.

Hall, D., A. Cork, S. Phythian, S. Chittamuru, B. Jayarama, M. Venkatesha, K. Sreedharan, P. Vinod Kumar, H. 
Seetharama and R. Naidu (2006) Identification of components of male-produced pheromone of coffee white stemborer Xylotrechus quadripes. J. Chem. Ecol. 32: 195-219.

Hanks, L. (1999) Influence of the larval host plant on reproductive strategies of cerambycid beetle. Annu. Rev. Entomol. 44: 483-505.

Hanks, L., T. Paine and J. Millar (1993) Host species preference and larval performance in the wood-boring beetle Phoracantha semipunctata F. Oecologia 95: 22-29.

Hines, J. and H. Heikkenen (1977) Beetles attracted to severed Virginia pine (Pinus virginiana Mill.). Environ. Entomol. 6: 123-127.

Ikeda, T., N. Enda, A. Yamane, K. Oda and T. Toyoda (1980) Attractants for the Japanese pine sawyer, Monochamus alternatus Hope (Coleoptera: Cerambycidae). Appl. Entomol. Zool. 15: 358-361.

Ikeda, T., E. Ohya, H. Makihara, T. Nakashima, A. Saitoh, K. Tate and K. Kojima (1993) Olfactory responses of Anaglyptus subfasciatus Pic and Demonax transilis Bates (Coleoptera: Cerambycidae) to flower scents. J. Jpn. For. Soc. 75: 108-112.

Kobayashi, H., A. Yamane and R. Iwata (2003) Mating behavior of the pine sawyer, Monochamus saltuarius (Coleoptera: Cerambycidae). Appl. Entomol. Zool. 38: 141-148.

Liendo, C., F. Morillo, P. Sánchez, W. Muñoz, J. Guerra, A. Cabrera and J. Hernández (2005) Olfactory behavior and electroantennographic responses of the cocoa beetle, Steirastoma breve (Coleoptera: Cerambycidae). Fla. Entomol. 88: 117-122.

Mendes, A. and J. García (1984) Biología do besouro do cacao Steirastoma breve (Sulzer) (Coleoptera: Cerambycidae). Rev. Theobroma 14: 61-68.

Nakamuta, K., W. Leal, T. Nakashima, M. Tokoro, M. Ono and M. Nakanishi (1997) Increase of trap catches by a combination of male sex pheromones and floral attractant in longhorned beetle, Anaglyptus subfasciatus. J. Chem. Ecol. 23: 1635-1640.

Nakashima, T., K. Nakamuta, H. Makihara, E. Ohya, M. Nakanishi and T. Ikeda (1994) Field responses of Anaglyptus subfasciatus Pic (Coleoptera: Cerambycidae) to benzyl acetate an structurally related esters. Appl. Entomol. Zool. 29: 421-425.

Reddy, G., R. Fettköther, U. Noldt and K. Dettner (2005) Enhancement of attraction and trap catches of the old-house borer, Hylotrepus bajulus (Coleoptera: Cerambycidae), by combination of male sex pheromone and monoterpenes. Pest Manag. Sci. 61: 699-704.
Ruther, J., T. Meiners and J. Steidle (2002) Rich en phenomena-lacking in terms. A classification of kairomones. Chemoecology 12: 161-167.

Sakai, M. and T. Yamasaki (1990) (+)-Juniperol and (+)-pimaral: Attractants for the cerambycid beetle, Monochamus alternatus Hope. J. Chem. Ecol. 16: 3383-3393.

Sakai, M. and T. Yamasaki (1991) (+)-cis-3-pinen-2-ol: Attractant for male cerambycid beetle, Monochamus alternatus Hope. J. Chem. Ecol. 17: 757-765.

Sánchez, P. and L. Capriles de Reyes (1979) Insectos asociados al cultivo del cacao en Venezuela. Estación Experimental de Caucagua. Centro Nacional de Investigaciones Agropecuarias. Boletín Técnico. $\mathrm{N}^{\circ} 11.56 \mathrm{pp}$.

Suckling, D., A. Gibb, J. Daly, X. Chen and E. Brockerhoff (2001) Behavioral and electrophysiological responses of Arhopalus tristis to burnt pine and other stimuli. $J$. Chem. Ecol. 27: 1091-1104.

Sweeney, J., P. De Groot, L. Macdonald, S. Smith, C. Cocquempot, M. Kenis and J. Gutowski (2004) Host volatile attractants and traps for detection of Tetropium fuscum (F.), Tetropium castaneum L., and other longhorned beetles (Coleoptera: Cerambycidae). Environ. Entomol. 33: 844-854.

Sweeney, J., J. Gutowski, J. Price and P. De Groot (2006) Effect of semichemical release rate, killing agent, and trap design on detection of Tetropium fuscum (F.) and other longhorn beetles (Coleoptera: Cerambycidae). Environ. Entomol. 35: 645-654.

Varshney, V., R. Dayal, R. Bhandari, K. Jyoti, A. Prasuna, A. Prasad and J. Yadav (2005) Behavioral response of the borer beetle Hoplocerambyx spinicornis to volatile compounds of the tree Shorea robusta. Chem. Biodiv. 2: 785-791.

Wang, Q., W. Zeng, L. Chen, J. Li and X. Yin (2002) Circadian reproductive rhythms, pair-bonding, and evidence for sex-specific pheromones in Nadezhdiella cantori (Coleoptera: Cerambycidae). J. Insect Behav. 15: 527-539.

Yasui, H. (2009) Chemical communication in mate location and recognition in the white-spotted longicorn beetle, Anoplophora malasiaca (Coleoptera: Cerambycidae). Appl. Entomol. Zool. 44: 183-194.

Yasui, H., T. Akino, M. Fukaya, S. Wakamura and H. Ono (2008) Sesquiterpene hydrocarbons: kairomones with a releaser effect in the sexual communications of the whitespotted longicorn beetle, Anoplophora malasiaca (Thomson) (Coleoptera: Cerambycidae). Chemoecology 18: 233-242. 